\title{
Towards a Biological Definition of Alzheimer Disease
}

\author{
Kurt A Jellinger, $M D^{*}$ \\ Institute of Clinical Neurobiology, Vienna, Austria
}

*Corresponding author: Kurt A Jellinger, MD, Institute of Clinical Neurobiology, Alberichgasse 5/13, A-1150 Vienna, Austria, Tel: +43-1-5266534, Fax: +43-1-5266534

\begin{abstract}
Alzheimer disease (AD), the most common form of dementia, is a heterogenous syndrome with various pathobiologically defined subtypes. The clinical diagnosis of probable $A D$ is enabled by the recent ATN biomarker system, but the definite diagnosis is only possible at post-mortem according to the updated NIA-AA criteria. The recent developments in the clinical and neuropathological diagnosis of $A D$ including its specific subtypes improving the evaluation of $A D$ and its impact on public health are briefly discussed.
\end{abstract}

\section{Keywords}

Alzheimer's disease diagnosis, ABC score, ATN biomarker system, Primary age-related tauopathy

Alzheimer disease (AD), the most common form of dementia that currently affects around 50 million people worldwide, was initiallyv defined as a clinico-pathological entity. However, AD is a heterogenous, multifactorial continuum with several pathobiologically defined subtypes, currently referred to as Alzheimer clinical syndrome [1]. AD is diagnosed definitely at autopsy by the deposition of $\beta$-amyloid $(A \beta)$ in extracellular plaques and in vasculature (cerebral amyloid angiopathy/CAA) and intraneuronal aggregation of abnormal hyperphosphorylated tau protein forming neurofibrillary tangles (NFT), associated by neuronal loss and cerebral atrophy, according to the updated NIA-AA " $A B C$ " criteria [2]. This " $A B C$ " score for $A D$ neuropathological changes combines " $A$ " for the phases of amyloid paques [3], " $B$ " for the NFT stages [4], and " $C$ " for the CERAD neuritic plaque score [5]. Non-demented patients usually show $A \beta$ phases $1-3$, Braak stages 0 to III/IV, and CAA stages $0-1$, while dementia is usually related to $A \beta$ stages $4-5$, Braak stages $\mathrm{V}-\mathrm{VI}$, and CAA stages 2-3. Comparison of the mini-mental stage examination (MMSE) scores with neuritic NFT stages in 200 consecutive autopsy cases of elderly persons (mean age $81.4 \pm 8.6$ years), showed that non-demented persons (MMSE 26-30) had no or only minimal tau pathology, and severely demented, no longer testable persons (MMSE around 0) showed a cluster of high tau pathology (Braak stages $\mathrm{V}$ and $\mathrm{VI}$ ), while mild to moderate dementia was associated with a wide range of Braak stages (Figure 1).

Diagnosis of probable $A D$ in life is possible using the new ATN biomarker system [6]. It is based on relationships between markers of $A \beta(A)$, tau pathology $(T)$ and neurodegeneration (N). A and T have diagnostic specificity for $A D, N$ is nonspecific for all neurodegenerative diseases. The neuropathological definition of $A D$ drives the ATN definition of $A D$ and requires the presence of amyloid and tau as evidenced by neuroimaging methods (PET) or cerebrospinal fluid (CSF) or plasma biomarkers for diagnosis, while $\mathrm{N}$ is shown by MRI, FDG PET or CSF total tau. $\mathrm{A}+, \mathrm{T}+$, and $\mathrm{N}+$ cases have a worse prognosis than negative (A-T-N-) cases. The biomarker profiles and categories of the Alzheimer continuum referring to individuals with biomarker designation of either $A D$ or Alzheimer pathologic change, are presented in Table 1. Prodromal AD is classified according to the ATN and NIA-AA criteria as follows: A-N- represents preclinical stage $0, A+N-$ preclinical stage $1, \mathrm{~A}+\mathrm{N}+$ preclinical stages 2 and 3 , and $\mathrm{A}-\mathrm{N}+$ for suspected non-Alzheimer's pathophysiology (SNAP) [8]. The risk of progressive cognitive deterioration differs considerably between the various types: $\mathrm{A}-\mathrm{N}-<\mathrm{A}+\mathrm{N}-<\mathrm{A}+\mathrm{T}-\mathrm{N}+(\mathrm{SNAP})<\mathrm{A}+\mathrm{T}+\mathrm{N}+[9]$.

During the last years, a new type of age-related dementia was described as primary age-related tauopathy (PART) [10]. It is morphologically characterized by tau pathology with Braak stages 0-IV, total or relative absence of amyloid ( $A \beta$ phases $0-2$ ) and total absence of neuritic plaques. It predominantly involves people over

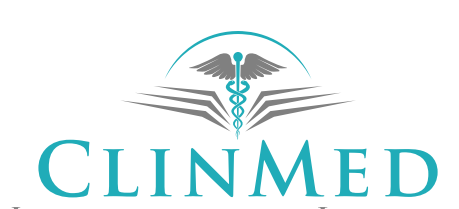

INTERNATIONAL LIBRARY

Citation: Jellinger KA (2020) Towards a Biological Definition of Alzheimer Disease. Int J Neurol Neurother 7:095. doi.org/10.23937/2378-3001/1410095

Accepted: January 06, 2020: Published: January 08, 2020

Copyright: (C) 2020 Jellinger KA. This is an open-access article distributed under the terms of the Creative Commons Attribution License, which permits unrestricted use, distribution, and reproduction in any medium, provided the original author and source are credited. 


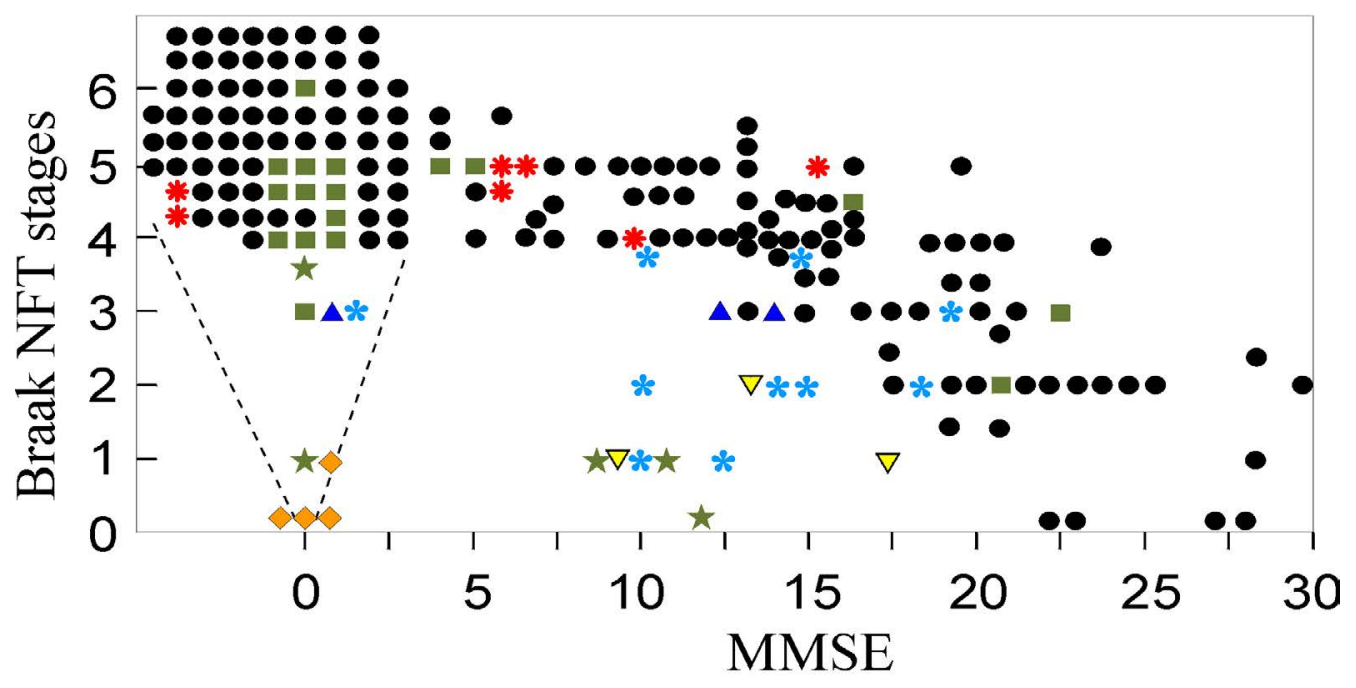

- Cases with "pure" AD pathology $(n=151)$

$\Delta$ Senile dem. - "plaques type" $(n=3)$

- Lewy body dementia $(n=17)$

$\star$ SID (Strategic Infarct dem.) $(\mathrm{n}=5)$

$\Delta$ FTD (Fronto-temp. deg.) $(\mathrm{n}=4)$

* MIX (DAT+MIXISAE; $n=7$ )

* SAE (M. Binswanger; $n=10$ )

$\nabla$ MIE (Multiinfarct dem.; $\mathrm{n}=3$ )

Figure 1: Relationship between Mini-Mental State Examination (MMSE) and Braak neuritic Alzheimer's disease stages in 200 consecutive autopsies of aged individuals (mean age at death $81.4 \pm 8.6$ years).

Table 1: Biomarker profiles and categories (modified after [7]).

\begin{tabular}{|c|c|c|}
\hline AT(N) profiles & Biomarker category & \\
\hline$A-T-(N)-$ & Normal AD biomarkers & \\
\hline$A+T-(N)-$ & Alzheimer's pathologic change (early stage) & \multirow{4}{*}{$\begin{array}{l}\text { Alzheimer's } \\
\text { continuum }\end{array}$} \\
\hline$A+T+(N)-$ & Alzheimer's disease & \\
\hline$A+T+(N)+$ & Alzheimer's disease & \\
\hline$A+T-(N)+$ & Alzheimer's and suspected non-Alzheimer's pathologic change (SNAP) & \\
\hline$A-T+(N)-$ & Non-AD pathologic change - other tauopathies & $?$ \\
\hline$A-T-(N)+$ & Non-AD pathologic change/neurodegenerative disorders & $?$ \\
\hline$A-T+(N)+$ & Non-AD pathologic change (PART) & \\
\hline
\end{tabular}

age 80 years and is associated with mild to moderate cognitive impairment [11]. The relationship between PART and classical AD is under discussion, since the composition of NFTs between both types is identical, with both $3 R$ and $4 R$ isoforms. PART is considered either as prodromal form of $A D$ or a subtype of AD-related disorders [12]. In PART, the lack of $A \beta$ is responsible for less severe tau aggregation and, thus, for lower Braak stages and less cognitive impairment than in classical $A D$, since $A \beta$ oligomers have been shown to potentiate tau aggregation by promoting tau seed uptake [13]. While classical $A D$ increases from the $7^{\text {th }}$ to the $9^{\text {th }}$ decade and later shows mild decrease, the frequency of PART increases after age 85 years.

A comparative study of clinical and neuropathlogical diagnoses of $A D$ in 3 epidemiologic samples reported a sensitivity of clinical or probable $A D$ of 93\% [14]. Meta-analysis of 20 (out of 1189) studies to distinguish autopsy-verified $A D$ from other dementias or healthy controls showed a sensitivity of $85.4 \%$ $(95 \% \mathrm{Cl} 80.9-90 \%)$ and a specificity of $77.7 \%(95 \% \mathrm{Cl}$
70.2-85.1\%). Values were higher for neuroimaging procedures and slightly lower for CSF biomarkers, while the combination of both resulted in higher values [15]. These data are related to two factors: (1) The various subtypes or variants of $A D$, and (2) The high frequency of co-morbidities in elderly people. The atypical variants of late and early onset $A D$ are presented in Table 2 . The three morphological subtypes are: Typical AD with tau pathology involving both cerebral cortex and hippocampus (74-82.5\% of the total, mean age at disease onset $79 \pm 4$ years, at death $81 \pm 9$ years), the limbic-predominant type (tau pathology mainly involving the medio-temporal lobe (9-15\% of total; mean age at onset $74 \pm 6$, at deat $85 \pm$ 4 years), and the hippocampal sparing type (8-10.8\% of the total; mean age at onset $68 \pm 10$, at death 76 \pm 8 years) [17]. The duration of disease is shortest in the limbic-predominant type and longest in typical $A D$, which also shows more severe dementia than the two others [18]. These subtypes show specific clusters of the regional NFT densities [19], which is related to the regional vulnerability of neuronal sub- 
Table 2: Atypical variants of late and early onset AD (modified after [16]).

\begin{tabular}{|l|l|l|l|l|}
\hline AD subtype & $\begin{array}{l}\text { Clinical } \\
\text { presentation }\end{array}$ & Pathology & $\begin{array}{l}\text { Progression } \\
\text { rate }\end{array}$ & $\begin{array}{l}\text { CSF Ab and tau } \\
\text { levels }\end{array}$ \\
\hline Typical LOAD (50-75\%) & $\begin{array}{l}\text { Amnestic/non- } \\
\text { amnestic }\end{array}$ & $\begin{array}{l}\text { Both hippocampal and } \\
\text { cortical ("both impaired") }\end{array}$ & Typical AD & Typical AD \\
\hline Limbic-predominant LOAD (15-35\%) & Amnestic & $\begin{array}{l}\text { Medial-temporal lobe } \\
\text { ("hippocampal”) }\end{array}$ & Slower & Similar \\
\hline $\begin{array}{l}\text { Hippocampal-sparing LOAD (10- } \\
25 \%)\end{array}$ & Non-amnestic & $\begin{array}{l}\text { "Cortical", sparing of } \\
\text { medial temporal lobes }\end{array}$ & Faster & Similar \\
\hline Minimal atrophy LOAD (10-17\%) & Unclear & Minimal & Slowest & A $\uparrow$, tau $\downarrow$ \\
\hline Typical EOAD $(75 \%)$ & $\begin{array}{l}\text { Amnestic/non- } \\
\text { amnestic }\end{array}$ & Hippocampal and cortical & Typical AD & Similar to typical AD \\
\hline Atypical EOAD $(25 \%)$ & Non-amnestic & Posterior cortical & Faster & Similar to typical AD \\
\hline
\end{tabular}

Table 3: Morphological diagnoses in consecutive Vienna autopsy series of $A$ ) demented and $B$ ) clinically diagnosed $A D$ patients.

\begin{tabular}{|c|c|c|}
\hline Morphologic diagnosis & (A) $\%$ & (B) $\%$ \\
\hline "Pure" AD (ABC 3/3/3) & 41.1 & 47.6 \\
\hline Subtypes of AD (plaque, limbic, PART) & 6.9 & 5.8 \\
\hline $\begin{array}{l}A D+C V D \text { (lacunar state, old/acute infarcts, } \\
\text { AH-sclerosis) }\end{array}$ & 16.5 & 22.9 \\
\hline$A D+$ cerebral hemorrhage (CAA) & 3.1 & 1.9 \\
\hline Lewy body variant AD/Diff, LB disease & 3.8 & 3.5 \\
\hline $\begin{array}{l}\text { AD + Parkinson pathol., PD, Incid. LBD, SN } \\
\text { lesions }\end{array}$ & 5.3 & 6.2 \\
\hline MIX type dem, (AD+MIE, +SAE, +SID) & 4.6 & 3.6 \\
\hline $\begin{array}{l}\text { AD + other pathologies (tumors, MS, MSA, } \\
\text { etc.) }\end{array}$ & 1.6 & 1.2 \\
\hline Alzheimer pathology total & 82.9 & 92.8 \\
\hline $\begin{array}{l}\text { Vascular dementia (MIE, SAE, SID, Ath. } \\
\text { scler.) }\end{array}$ & 10.7 & 3.3 \\
\hline $\begin{array}{l}\text { Other disorders (Huntington disease, FTD, } \\
\text { CJD, others) }\end{array}$ & 5.5 & 3.1 \\
\hline Nothing abnormal beyond age & 0.9 & 0.8 \\
\hline Non-Alzheimer pathologies & 17.1 & 7.2 \\
\hline Total $n(100 \%)$ & 1700 & 890 \\
\hline
\end{tabular}

types to tau pathology, those in the entorhinal and other regions of the hippocampus showing early, basal forebrain mild, and neurons in cerebral cortex and locus ceruleus late stages of involvement [16]. Another major reason for the difficulties in clinical diagnosis of $A D$ is the high frequency of co-morbidities or mixed pathologies in the aged brain. Table 3 shows the morphological diagnoses in a consecutive autopsy series of 1700 elderly demented patients (A) and those with clinical diagnosis of $A D(B)$. AD-typical pathology was present in $82.9 \%$ of all demented people and in $92.8 \%$ of those with the clinical diagnosis of $A D$, but only half of them showed "pure" AD-pathology $(A B C 3 / 3 / 3)$, while all the others were either atypical forms or showed additional cerebrovascular lesions, cerebral hemorrhages, Lewy pathology or other mixed pathologies, while vascular dementia in this cohort amounted for only 10.7 and $3.3 \%$ re- spectively. An earlier study of Alzheimer patients in clinical trials revealed pure Alzheimer pathology in only $31 \%$ and multiple pathologies in $63 \%$, no pathological changes in 1\% [20]. Similar co-morbidities in 1153 patients with pathological diagnosis of AD were shown recently [21]. This clinical and morphological heterogeneitiy of $A D$ is due to multiple pathogenic factors - "upstream" genotypes causing co-morbidities, "downstream" disease-modifying gene variants (MPTP, H2 haplotype, APOE, TREM and GRN variants) - which induce misfolding of tau, A $\beta$, TDP 32 , and others, resulting in various disease phenotypes [22].

In conclusion, AD is a multifactorial, heterogenous disorder, morphologically defined by the deposition of $A \beta$ and hyperphosphorylated tau, that is definitely diagnosed at post-mortem according to the updated NIA-AA criteria, while diagnosis of probable AD in life is possible by the ATN biomarker system. The introduction of the ATN biomarker system has increased the accuracy of clinical diagnosis of AD compared to studies before general use of biomarkers including CSF and neuroimaging markers, such as $\beta$-amyloid and tau PET or multisystem neuroimaging methods. However, the validity of the current ATN biomarker system for the intra vitam diagnosis of $A D$ and its differentiation from other dementia syndromes awaits further multicenter clinico-pathological studies using all currently available methods.

The still low diagnostic accuracy of the clinical diagnosis of AD despite the new ATN biomarker criteria is caused by the fact that the Alzheimer clinical syndrome includes several pathobiologically defined entities or subtypes which are clinically and morphologically different from each other:

- Alzheimer continuum (abnormal $A \beta$ regardless of tau status)

- Alzheimer pathological changes ( $A \beta$ but normal tau - previously referred to as amyloid-predominant AD)

- Neurodegeneration but negative A (SNAP)

- PART (abnormal tau but negative $A \beta$ ) 
- Limbic predominant AD (tau pathology mainly involving the mediotemporal lobe - hippocampus)

- Hippocampal-sparing AD ("cortical sparing" of medial temporal lobes),

- Classical AD (abnormal $A \beta$ and tau-pathology, the latter involving both cortex and hippocampus).

The prevalence of biological $A D$ is greater than clinical probable $A D$ at any age, in particular at age $85+$ years [1]. These facts and the increasing incidence of $A D$ illustrate its consequences on public health. In order to increase the sensitivit and specificity of the new ATN biomarker system, more extensive clinicopathological studies in well defined patient cohorts will be necessary, with post mortem studies using the updated NIA-AA criteria. Similar proposals have recently been published for validating the criteria for the diagnosis of 4-repeat tauopathies [23]. Therefore, further interdisciplinary studies to improve our knowledge about the pathogenesis and to promote methods for early diagnosis of $A D$ as basis for further preventive and successful therapeutic measures are urgently needed.

\section{Conflict-of-Interest Statement}

The author has no conflict of interest to declare.

\section{Acknowledgement}

The study was supported by the Society for Support of Research in Experimental Neurology, Vienna, Austria.

\section{References}

1. Jack CR Jr, Therneau TM, Weigand SD, Wiste HJ, Knopman DS, et al. (2019) Prevalence of biologically vs clinically defined Alzheimer spectrum entities using the National Institute on Aging-Alzheimer's Association Research Framework. JAMA Neurol.

2. Montine TJ, Phelps $\mathrm{CH}$, Beach TG, Bigio EH, Cairns NJ, et al. (2012) National Institute on Aging-Alzheimer's Association guidelines for the neuropathologic assessment of Alzheimer's disease: a practical approach. Acta Neuropathol 123: 1-11.

3. Thal DR, Rub U, Orantes M, Braak H (2002) Phases of A beta-deposition in the human brain and its relevance for the development of AD. Neurology 58: 1791-1800.

4. Braak H, Braak E (1991) Neuropathological stageing of Alzheimer-related changes. Acta Neuropathol 82: 239-259.

5. Mirra SS, Hart MN, Terry RD (1993) Making the diagnosis of Alzheimer's disease. A primer for practicing pathologists. Arch Pathol Lab Med 117: 132-144.

6. Knopman DS, Haeberlein SB, Carrillo MC, Hendrix JA, Kerchner G, et al. (2018) The National Institute on Aging and the Alzheimer's Association Research Framework for Alzheimer's disease: Perspectives from the research roundtable. Alzheimers Dement 14: 563-575.

7. Jack CR Jr, Bennett DA, Blennow K, Carrillo MC, Dunn B, et al. (2018) NIA-AA Research Framework: Toward a biological definition of Alzheimer's disease. Alzheimers Dement 14: 535-562.

8. Jack CR Jr, Knopman DS, Chetelat G, Dickson D, Fagan
AM, et al. (2016) Suspected non-Alzheimer disease pathophysiology - concept and controversy. Nat Rev Neurol 12: 117-124.

9. Caroli A, Prestia A, Galluzzi S, Ferrari C, van der Flier WM, et al. (2015) Mild cognitive impairment with suspected nonamyloid pathology (SNAP): Prediction of progression. Neurology 84: 508-515.

10. Crary JF, Trojanowski JQ, Schneider JA, Abisambra JF, Abner EL, et al. (2014) Primary age-related tauopathy (PART): a common pathology associated with human aging. Acta Neuropathol 128: 755-766.

11. Besser LM, Kukull WA, Teylan MA, Bigio EH, Cairns NJ, et al. (2018) The revised National Alzheimer's Coordinating Center's Neuropathology form-available data and new analyses. J Neuropathol Exp Neurol 77: 717-726.

12. Jellinger KA (2016) Commentary on the paper "PART, a Distinct Tauopathy, Different from Classical Sporadic Alzheimer Disease. J Clin Cell Immunol 7: 1000480.

13. Shin WS, Di J, Cao Q, Li B, Seidler PM, et al. (2019) Amyloid beta-protein oligomers promote the uptake of tau fibril seeds potentiating intracellular tau aggregation. Alzheimers Res Ther 11: 86.

14. Plassman BL, Khachaturian AS, Townsend JJ, Ball MJ, Steffens DC, et al. (2006) Comparison of clinical and neuropathologic diagnoses of Alzheimer's disease in 3 epidemiologic samples. Alzheimers Dement 2: 2-11.

15. Cure S, Abrams K, Belger M, Dell'agnello G, Happich M (2014) Systematic literature review and meta-analysis of diagnostic test accuracy in Alzheimer's disease and other dementia using autopsy as standard of truth. J Alzheimers Dis 42: 169-182.

16. Mrdjen D, Fox EJ, Bukhari SA, Montine KS, Bendall SC, et al. (2019) The basis of cellular and regional vulnerability in Alzheimer's disease. Acta Neuropathol 138: 729-749.

17. Murray ME, Graff-Radford NR, Ross OA, Petersen RC, Duara $R$, et al. (2011) Neuropathologically defined subtypes of Alzheimer's disease with distinct clinical characteristics: A retrospective study. Lancet Neurol 10: 785-796.

18. Jellinger KA (2012) Neuropathological subtypes of Alzheimer's disease. Acta Neuropathol 123: 153-154.

19. Petersen C, Nolan AL, de Paula Franca Resende E, Miller Z, Ehrenberg AJ, et al. (2019) Alzheimer's disease clinical variants show distinct regional patterns of neurofibrillary tangle accumulation. Acta Neuropathol 138: 597-612.

20. Wang BW, Lu E, Mackenzie IR, Assaly M, Jacova C, et al. (2012) Multiple pathologies are common in Alzheimer patients in clinical trials. Can J Neurol Sci 39: 592-599.

21. DeTure MA, Dickson DW (2019) The neuropathological diagnosis of Alzheimer's disease. Mol Neurodegener 14: 32.

22. Nelson PT, Trojanowski JQ, Abner EL, Al-Janabi OM, Jicha GA, et al. (2016) "New Old Pathologies": AD, PART, and cerebral age-related TDP-43 with sclerosis (CARTS). J Neuropathol Exp Neurol 75: 482-498.

23. Respondek G, Grimm MJ, Piot I, Arzberger T, Compta Y, et al. (2019) Validation of the movement disorder society criteria for the diagnosis of 4-repeat tauopathies. Mov Disord online.
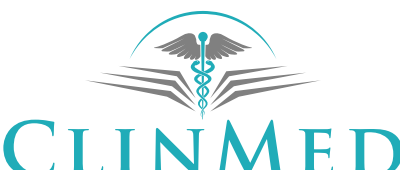

INTERNATIONAL LIBRARY 